\title{
Thrombolysis for cerebral ischemia
}

\author{
Jennifer E. Fugate, Elias A. Giraldo and Alejandro A. Rabinstein*
}

Department of Neurology, Mayo Clinic, Rochester, MN, USA

Edited by:

S. Andrew Josephson, University of California at San Francisco, USA

Reviewed by:

Jose Biller, Loyola University Medical Center, USA

Kevin N. Sheth, University of Maryland School of Medicine, USA

\section{*Correspondence:}

Alejandro A. Rabinstein, 200 First Street SW, Rochester, MN 55905, USA.

e-mail: rabinstein.alejandro@mayo.edu
The care for patients with acute ischemic stroke has been revolutionized by the clinical application of fibrinolysis. Intravenous recombinant tissue plasminogen activator (rt-PA) has been proven to improve functional outcomes following acute ischemic stroke and can be administered to a select group of patients up to $4.5 \mathrm{~h}$ after symptom onset. Time from symptom onset to thrombolysis is the most important determinant of the success of treatment, with greatest efficacy if given within $90 \mathrm{~min}$. Hospitals should implement standardized processes and protocols for acute stroke to guide immediate patient assessment, brain imaging, drug administration, and post-thrombolysis care. In this article we review the clinical application of thrombolysis, care of acute stroke patients, current evidence regarding fibrinolysis, and future direction of penumbral imaging to select candidates for reperfusion therapies.

Keywords: acute stroke, cerebrovascular, thrombolysis, t-PA
The concept of pharmacological fibrinolysis for the treatment of acute ischemic stroke developed from the finding that early reperfusion improved outcomes in various experimental animal models of intracranial vessel occlusion and the recognition that the mechanisms for endogenous fibrinolysis in humans are often insufficient to prevent brain infarction in many patients (Meschia et al., 2002). The clinical application of fibrinolysis revolutionized ischemic stroke care by offering an effective treatment for a disease in which previously all medical efforts were focused on prevention of recurrent events, avoidance of secondary complications, and rehabilitation.

\section{MECHANISMS OF FIBRINOLYSIS}

When a clot is formed, a plasma protein called plasminogen gets trapped within it. The injured tissues and vascular endothelium then slowly release tissue plasminogen activator $(\mathrm{t}-\mathrm{PA})$ which in turn converts plasminogen to plasmin. Plasmin is a potent proteolytic enzyme that digests fibrin (the main protein component of the clot) into soluble fragments (fibrin degradation products). This process ensures the clot dissolution and protects blood flow, particularly in the microcirculation.

\section{FIBRINOLYSIS FOR THE TREATMENT OF ISCHEMIC STROKE THE EVIDENCE}

Early intravenous administration of recombinant tissue plasminogen activator (rt-PA, Alteplase) has been proven to improve functional outcome after acute ischemic stroke (Adams et al., 2007). The pivotal trial leading to the international approval of intravenous rt-PA for the treatment of cerebral ischemia was the NINDS rt-PA Stroke Study (NINDS rt-PA Stroke Study Group , 1995). In this trial, 624 patients were randomized to receive intravenous rt-PA $(0.9 \mathrm{mg} / \mathrm{kg}$, maximum $90 \mathrm{mg})$ or placebo within $3 \mathrm{~h}$ of stroke symptom onset. Treatment with intravenous rt-PA was associated with at least 30\% increase in the chances of achieving functional independence with complete or nearly complete neurological recovery at 3 months (NINDS rt-PA Stroke Study Group , 1995). The main risk of treatment was symptomatic intracerebral hemor- rhage, which occurred in $6.4 \%$ of patients treated with rt-PA versus $0.6 \%$ of patients who received placebo, but it did not result in an increase in mortality among rt-PA-treated patients. Efficacy was greatest for patients treated within $90 \mathrm{~min}$ of symptom onset. For patients treated within $90 \mathrm{~min}$ the odds ratio for complete recovery was 2.11 compared with an odds ratio of 1.69 for patients treated within 91-180 min (Marler et al., 2000). Functional benefit was sustained at 1 year (Kwiatkowski et al., 1999). Subgroup analyses confirmed that the efficacy of intravenous rt-PA extended to all patients meeting the trial inclusion and exclusion criteria, including older patients with severe strokes at presentation (NINDS rt-PA Stroke Study Group , 1995).

Shortly after publication of the NINDS trial, rt-PA was approved for intravenous use in patients with acute ischemic stroke in the USA mostly following the patient selection criteria of NINDS study. An additional radiological exclusion criterion was added based on the finding that the presence of large early ischemic changes on baseline CT scan was associated with higher risk of symptomatic intracranial hemorrhage and results from earlier European studies that suggested poorer outcomes in patients with multilobar low attenuation changes(von Kummer and Hacke, 1992) which had led to the exclusion of these patients from subsequent European trials. Since then, treatment with intravenous rt-PA has gained acceptance across the globe and its effectiveness has been confirmed in multiple post-marketing observational studies.

The largest of these observational studies has been the SITSMOST (Wahlgren et al., 2007), which enrolled nearly 6,500 patients from 14 European countries. Intravenous fibrinolysis with rt-PA was at least as safe and effective in routine clinical practice as it had been in the randomized trials (Wahlgren et al., 2007; Wahlgren et al., 2008b). Over three-quarters of treated patients had moderate to severe strokes at baseline and 55\% were independent at 3 months despite only $10.6 \%$ being treated within $90 \mathrm{~min}$ (versus half of the rt-PA group in the NINDS trial). Even centers with limited experience on the administration of fibrinolysis for acute stroke achieved good results when adhering to the accepted indications and con- 
traindications. The risk of intracranial hemorrhage, defined using various criteria, was acceptably low. Substantial neurological decline from brain hemorrhage only occurred in $1.7 \%$ of patients.

Although intravenous fibrinolysis has become standard of care for emergency treatment of patients with acute ischemic stroke, only a small minority of these patients receive the therapy. The main reason for the limited application of this effective intervention in clinical practice is that patients often arrive to the Emergency Department too late. As a consequence, there has been a lot of interest in extending the therapeutic window for acute reperfusion therapies, including intravenous rt-PA.

A pooled analysis of six major trials evaluating the effectiveness of intravenous rt-PA for acute ischemic stroke within up to $6 \mathrm{~h}$ from symptom onset suggested that fibrinolysis could produce clinical benefit when administered beyond $3 \mathrm{~h}$ (Hacke et al., 2004). In fact, this analysis showed that the benefit was much greater over the first $90 \mathrm{~min}$ from symptom onset, but much more similar when time to treatment was 91-180 and 181-270 min. These findings provided the rationale for the design of the ECASS III trial, a multi-center, randomized trial conducted in Europe to evaluate intravenous rt-PA versus placebo administered between 3 and $4.5 \mathrm{~h}$ after onset of ischemic stroke symptoms (Hacke et al., 2008). A total of 821 patients were enrolled, nearly one-third more than in the NINDS trial. Treatment with rt-PA was associated with a significant improvement in the rate of favorable functional outcome using various scales. Overall, the chances to regain full independence were $28 \%$ higher among patients treated with rt-PA and 14 patients had to be treated for one additional patient to achieve a favorable outcome. Mortality was not significantly different between the groups, but slightly higher in the placebo arm. The rate of symptomatic intracranial hemorrhage as defined by the NINDS criteria was $7.9 \%$ in the rt-PA group (versus $6.4 \%$ in the NINDS trial), but only $2.4 \%$ of them were considered to have worsened because of the bleeding. A subsequent analysis confirmed the efficacy of rt-PA in various subgroups treated within the 3-4.5 h window, including patients of older age and across all severities of stroke (Bluhmki et al., 2009). Intravenous fibrinolysis with rt-PA within 3 and $4.5 \mathrm{~h}$ was also shown to be safe in large European observational study (SITS-ISTR) which included over 650 patients treated in that time window (Wahlgren et al., 2008a). Therefore, intravenous rt-PA should be considered for selected patients with symptom duration between 3 and $4.5 \mathrm{~h}$. It should be noted that there are additional exclusion criteria for the 3-4.5 h time window, as patients with certain characteristics were not studied. These include age $>80$ years, very severe deficits at onset (NIHSS >25), combination of history of previous stroke and diabetes mellitus, and oral anticoagulation regardless of INR at presentation.

\section{PATIENT EVALUATION AND SELECTION}

Acute stroke patients must be evaluated emergently for consideration of reperfusion treatments. Hospitals need to implement a stroke code process to streamline immediate patient assessment, brain imaging, and drug administration. Development of critical care pathways (ideally starting from assessment in the field by paramedics or other first responders), easily accessible written protocols, and order sets is highly useful to ensure rapid and effective evalua- tion and treatment. Hospitals should monitor their performance to recognize areas for improvement and to ensure consistent compliance with the recommended time metrics (Table 1).

Strict adherence to the prescribed criteria for patient selection is crucial to avoid complications and optimize the likelihood of benefit from intravenous fibrinolysis. Table 2 presents the indications and contraindications for treatment with intravenous rt-PA. Notice that some additional contraindications should be respected when contemplating the use of rt-PA between 3 and $4.5 \mathrm{~h}$. Treatment in patients without a suspected coagulopathy (e.g., no

Table 1 |Target times from acute stroke presentation to fibrinolytic treatment.

\begin{tabular}{ll}
\hline Step of care & Target time \\
\hline Evaluation by physician & $10 \mathrm{~min}$ \\
Brain imaging & $25 \mathrm{~min}$ \\
Interpretation of brain imaging (door-to-interpretation) & $45 \mathrm{~min}$ \\
Start of fibrinolysis (door-to-needle) & $60 \mathrm{~min}$
\end{tabular}

Table 2 | Indications and contraindications for intravenous rt-PA in acute ischemic stroke.

\section{Indications}

Diagnosis of ischemic stroke causing a measurable neurological deficit

Onset of symptoms $<4.5 \mathrm{~h}$ before initiation of treatment

\section{CONTRAINDICATIONS}

\section{Clinical}

Sustained hypertension above 180/110 mm Hg

Symptoms suggestive of subarachnoid hemorrhage

Previous history of intracranial hemorrhage

ST elevation myocardial infarction within the previous 3 months

Major head trauma or stroke within the previous 3 months

Major surgery within the previous 14 days

Gastrointestinal or urinary tract hemorrhage within the previous 21 days

Arterial puncture at a non-compressible site within the previous 7 days

Active bleeding or acute traumatic fracture on examination

Seizure at onset with suspected postictal deficits

Minor or rapidly improving neurological deficits

Radiological

Head CT showing hemorrhage or multilobar infarction (i.e.,

hypodensity involving $>1 / 3$ of the cerebral hemisphere

\section{Laboratory}

Oral anticoagulation with INR $>1.7^{*}$

Heparin within previous $48 \mathrm{~h}$ with elevated current aPTT

Platelet count $<100,000$ per $\mathrm{mm}^{3}$

Blood glucose level $<50 \mathrm{mg} / \mathrm{dL}(2.7 \mathrm{mmol} / \mathrm{L})$ at presentation with

improving deficits following correction of hypoglycemia

Additional contraindications for treatment between 3 and $4.5 \mathrm{~h}$

Age $>80$ years

Very severe deficits at onset (NIHSS score $>25$ )

Combination of previous stroke and diabetes mellitus

* Oral anticoagulation regardless of current INR should be considered a contraindication for treatment between 3 and $4.5 \mathrm{~h}$. 
recent or current administration of anticoagulants, no history of thrombocytopenia, end-stage liver disease or hematologic disorder) should not be delayed for laboratories with long turnaround times. Thrombolysis can be safely administered in these patients before the results of clotting tests are available (Rost et al., 2009). Other neurologic conditions can mimic ischemic stroke (e.g., migraine, seizure, or conversion disorder), but fear of misdiagnosis should not prevent initiation of intravenous thrombolysis if the clinician has reasonable concern for acute ischemic stroke. The risk of intracranial hemorrhage in those treated with intravenous rt-PA who present with acute neurologic symptoms that are found to be caused by other conditions is not well studied, but appears to be low. A recent retrospective study found zero instances of intracranial hemorrhage in patients with stroke mimics (Chernyshev et al., 2010).

The importance of careful determination of time of symptom onset cannot be overemphasized. Current guidelines on rt-PA administration are based on the definition of symptom onset as the last time that the patient was symptom-free or at his/her previous baseline (Adams et al., 2007). For patients who wake up with symptoms, the time of onset is considered the last time the patient was awake and without the symptoms. A recent transient ischemic attack similar to the current symptoms is generally not considered a contraindication for fibrinolysis; the clock can be reset to the time of onset of the new symptoms as long as there is clear knowledge that the previous symptoms resolved fully.

Some factors initially listed among the exclusion criteria for intravenous fibrinolysis in the seminal trials are no longer considered to be contraindications in practice. For instance, the report of a seizure at the onset of deficits should not preclude fibrinolysis as long as the treating physician is convinced that the persistent deficits are secondary to a stroke and not merely a postictal phenomenon (Adams et al., 2007). A similar reasoning might applied to hypoglycemic patients who fail to improve after administration of dextrose. One should also be careful when deciding not to treat a stroke patient with fibrinolysis because of mild or rapidly improving symptoms. All too often, these patients subsequently suffer permanent disability from those strokes (Barber et al., 2001).

Interpretation of brain imaging in the emergency setting has the primary objective of excluding intracranial hemorrhage. Noncontrast CT scan of the head is sufficient for this goal and emergency treatment should not be delayed in order to obtain more advanced imaging modalities (such as multimodality MRI and multimodality CT) (Adams et al., 2007). Apart from hemorrhage, only the presence of multilobar hypodensity (involving more than $1 / 3$ of the cerebral hemisphere) should be considered a radiological contraindication for fibrinolysis (Figure 1). Other CT findings may have prognostic value but they do not negate the benefit of fibrinolysis and should not preclude its use (Figure 2). For instance, the presence of a hyperdense middle cerebral artery sign is associated with worse prognosis (Qureshi et al., 2006) and higher risk of hemorrhage after fibrinolysis (Derex et al., 2005), but intravenous rt-PA can still be useful for these patients (Qureshi et al., 2006). Other early signs of brain ischemia can often be seen when the CT scan is assessed in detail, such as loss of insular ribbon, obscuration of the lenticular nucleus, loss of gray-white matter differentiation,
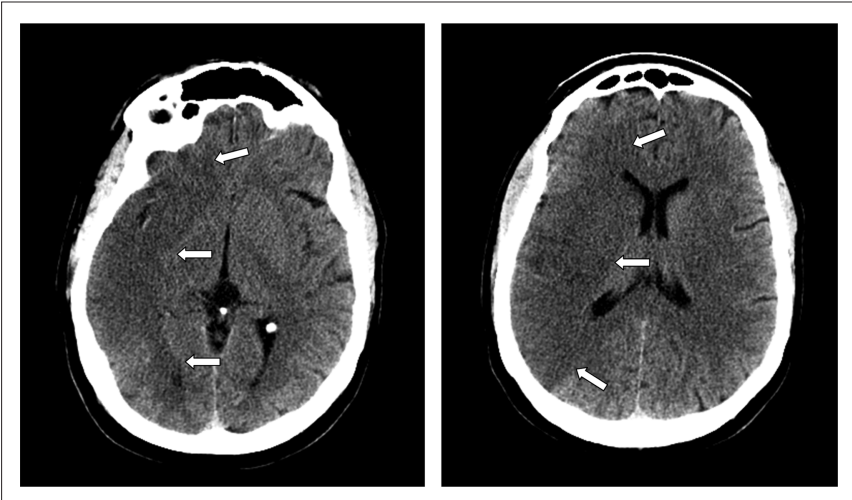

FIGURE 1 | CT scan of the head without contrast showing multilobar hypodensity in the right hemisphere (arrows).
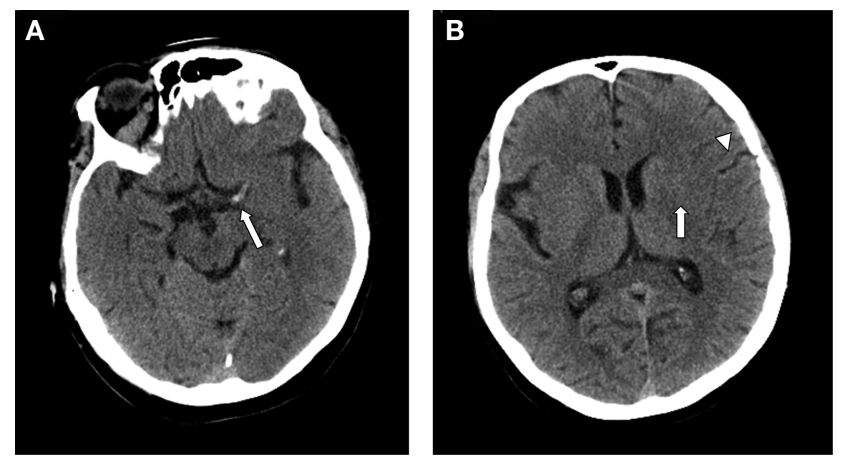

FIGURE 2 | (A) Axial non-contrast CT of the head demonstrates a left hyperdense middle cerebral artery sign indicative of acute thrombus (arrow). (B) CT scan of the head without contrast showing effacement of sulci and Sylvian fissure (arrowhead) and loss of distinction of the margins of the left lenticular nucleus (arrow)

and sulcal effacement. However, these signs do not have the same implication as areas of definite hypodensity because they probably indicate focal tissue edema rather than established infarction (Muir et al., 2006). Interpretation of brain imaging should be performed by a physician with expertise reading brain scans, but formal training in neuroradiology is not required.

Adequate control of blood pressure before, during and after administration of intravenous fibrinolysis must be achieved to reduce the risk of intracranial bleeding. Table 3 summarizes the recommendations for blood pressure control. Most stroke specialists deem administration of fibrinolysis unsafe for patients who require sodium nitroprusside infusion to lower the blood pressure below 185/110 mm Hg in the Emergency Department.

\section{ADMINISTRATION OF FIBRINOLYSIS AND POST-FIBRINOLYSIS CARE}

Infusion of the fibrinolytic agent should be started in the Emergency Department without delay as soon as the patient is determined to be a good treatment candidate. The dose of rt-PA is $0.9 \mathrm{mg} /$ $\mathrm{kg}$ (maximum $90 \mathrm{mg}$ ) over $60 \mathrm{~min}$ with $10 \%$ of the total dose given as a bolus over $1 \mathrm{~min}$. After fibrinolysis, the patient should be admitted to a Stroke Unit for strict neurological monitoring by specialized nurses. Post-fibrinolytic management should be 
Table 3 | Management of arterial hypertension in patients with acute ischemic stroke who are candidates for fibrinolysis.

Before fibrinolysis
If $\mathrm{SBP}>185 \mathrm{~mm} \mathrm{Hg}$ or $\mathrm{DBP}>110 \mathrm{~mm} \mathrm{Hg}$
Labetalol $10-20 \mathrm{mg}$ IV over $1-2 \mathrm{~min}$ (may repeat once)
or
Nicardipine infusion at $5-15 \mathrm{mg} / \mathrm{h}$
If BP controlled, administer fibrinolysis
If BP still >185/110 $\mathrm{mm} \mathrm{Hg}$, do NOT proceed with fibrinolysis

\section{After fibrinolysis \\ If SBP 180-230 mm Hg or DBP 105-120 mm Hg \\ Labetalol 10-20 mg IV over 1-2 min, \\ may repeat every 10-20 min up to $300 \mathrm{mg}$ over $24 \mathrm{~h}$ \\ or \\ Labetalol 10-20 mg IV followed by infusion at 2-8 $\mathrm{mg} / \mathrm{min}$ \\ or \\ Nicardipine infusion at $5-15 \mathrm{mg} / \mathrm{h}$ \\ If $\mathrm{SBP}>230 \mathrm{~mm} \mathrm{Hg}$ or $\mathrm{DBP}>120 \mathrm{~mm} \mathrm{Hg}$ \\ Sodium nitroprusside infusion at $0.5-3 \mathrm{mcg} / \mathrm{kg} / \mathrm{min}$ (doses of up \\ to $10 \mathrm{mcg} / \mathrm{kg} / \mathrm{min}$ can be safely administered for up to $10 \mathrm{~min}$ )}

This protocol also applies to other forms of reperfusion therapy apart from intravenous rt-PA.

$B P$, blood pressure; $S B P$, systolic blood pressure; DBP, diastolic blood pressure.

ideally guided by a written protocol to ensure optimal care and avoid risks. Patients should be kept on cardiac telemetry for at least the first $24 \mathrm{~h}$.

Neurologic assessments and blood pressure measurements should be performed every $15 \mathrm{~min}$ during the infusion, followed by every $30 \mathrm{~min}$ for the first $6 \mathrm{~h}$, and then hourly until $24 \mathrm{~h}$ after treatment. The rationale for such close blood pressure monitoring is that excessive hypertension in patients treated with intravenous rt-PA is associated with the development of symptomatic hemorrhagic transformation. Hypertension in the $24 \mathrm{~h}$ post-fibrinolysis is preferably treated with intravenous labetalol or nicardipine infusion. If systolic blood pressure exceeds $230 \mathrm{~mm}$ Hg or diastolic blood pressure exceeds $120 \mathrm{~mm}$ $\mathrm{Hg}$, intravenous continuous infusions of antihypertensives (e.g., sodium nitroprusside) should be considered. If the patient develops severe headache, vomiting, or acute refractory hypertension (BP >180/110), an emergency head CT should be obtained.

Bleeding complications in general and intracranial hemorrhage in particular are the most common and feared adverse events after intravenous fibrinolysis. Yet, disabling or fatal intracranial hemorrhages after fibrinolysis typically occur in older patients with severe deficits and large areas of ischemia at presentation (Albers et al., 2006; Saver, 2007). In other words, severe brain hemorrhages usually complicate fibrinolytic therapy in patients who already had very poor prognosis from presentation. As a consequence, few patients are actually harmed by intravenous rt-PA (number needed to harm has been estimated to be 126 for disabled or fatal outcome and 36.5 for worsened outcome among patients treated within $3 \mathrm{~h}$ of symptom onset) (Saver, 2007).

Strict monitoring of blood glucose (with insulin as needed to maintain levels between 140 and $180 \mathrm{mg} / \mathrm{dL}$ ) and avoidance of hyperthermia are essential measures of supportive care.
Hyperglycemia and fever have been independently associated with increased risk of poor outcome in the setting of acute ischemic stroke. Any fever should be investigated for source as it may be the first sign of an infectious complication such as pneumonia. Follow-up brain imaging should be obtained at $24 \mathrm{~h}$ after treatment, prior to the initiation of antithrombotics (antiplatelet agents or anticoagulants).

Additional complications from rt-PA include angioedema, which may cause partial airway obstruction, and, very rarely, myocardial rupture in patients with previous large myocardial infarctions.

\section{PREDICTORS OF OUTCOME AFTER INTRAVENOUS FIBRINOLYSIS}

Older age, worse neurological deficits (i.e., higher NIHSS score) and disturbances of consciousness at presentation, higher admission blood glucose level, and early ischemic changes and hyperdense middle cerebral artery sign on baseline CT scan are the main predictors of poor outcome upon initial evaluation (NINDS rt-PA Stroke Study Group , 1995; Bruno et al., 2002; Heuschmann et al., 2004; Qureshi et al., 2006; Wahlgren et al., 2008b; Mateen et al., 2009). Time to fibrinolysis has a strong inverse association with functional outcome across strokes of different severity (Marler et al., 2000; Hacke et al., 2004). Hyperglycemia and intracranial hemorrhage predict hyperacute clinical worsening after fibrinolysis (Leigh et al., 2004). Lack of improvement at $24 \mathrm{~h}$ portends worse outcome at 3 months (Saposnik et al., 2004). Hyperglycemia, time to fibrinolytic therapy, and cortical involvement have been associated with lack of improvement during the first day (Saposnik et al., 2004). The detrimental effects of hyperglycemia may be at least partially explained by lower rates of recanalization, probably related to a hyperglycemia-induced decrease in fibrinolytic activity (Ribo et al., 2005).

The main predictors of symptomatic intracranial hemorrhage are older age - although intravenous rt-PA can be administered to selected octogenarians and even non-egenarians with acceptable safety - (Sylaja et al., 2006; Mateen et al., 2010), higher initial NIHSS, larger area of ischemia, and higher blood glucose levels (Kidwell et al., 2002; Hacke et al., 2004; Albers et al., 2006). Longer time to fibrinolysis has been associated with higher risk of intracranial hemorrhage in some(Kidwell et al., 2002) but not all studies (Hacke et al., 2004). Higher systolic blood pressure may also increase the risk of intracranial hemorrhage (Wahlgren et al., 2008b), but especially when currently recommended parameters for blood pressure controlled are not respected. Other protocol violations, most notably the use of antithrombotic agents during the first $24 \mathrm{~h}$, can markedly increase the risk of hemorrhage (Katzan et al., 2000).

\section{NOVEL STRATEGIES FOR INTRAVENOUS FIBRINOLYSIS SELECTION OF CANDIDATES FOR INTRAVENOUS FIBRINOLYSIS USING PENUMBRAL IMAGING}

There is strong physiological rationale to support the concept that imaging of the ischemic penumbra with MRI diffusion-weighted (DWI) and perfusion-weighted (PWI) or CT perfusion (CTP) can extend the therapeutic window for reperfusion therapies, including fibrinolysis. Proponents of this model argue that documentation of persistent ischemic penumbra (i.e., hypoperfused but salvageable tissue) should represent a solid indication for reperfusion treatments 


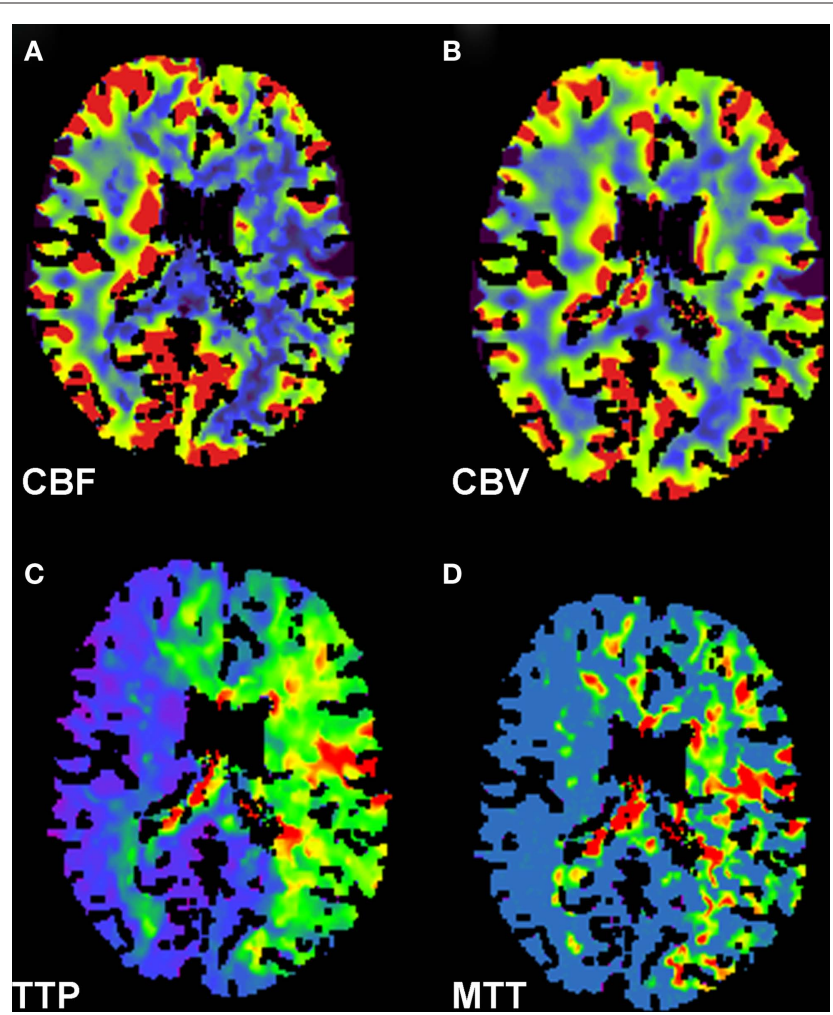

FIGURE 3 | CT perfusion scan of the head demonstrates findings consistent with large ischemic penumbra. Decreased cerebral blood flow (A), preserved cerebral blood volume (B), and prolonged time to peak (C) and mean transit time (D) in the left middle cerebral and bilateral anterior cerebral artery distributions are shown

regardless of duration of symptoms. A comparison of CTP sequences of mean transit time, cerebral blood flow, and cerebral volume may identify whether there is salvageable ischemic penumbra or if the infarct has been completed (Figure 3). Assuming that brain imaging can reliably recognize penumbral tissue and discriminate patients at excessive risk for bleeding in the infarct core, the concept should be valid. However, these assumptions remain to be proven.

DEFUSE was a prospective observational study of 74 patients treated with intravenous rt-PA between 3 and $6 \mathrm{~h}$ after symptom onset (Albers et al., 2006). All patients underwent MRI with DWI-PWI and MR angiogram before and a few hours after fibrinolysis, but all patients were treated regardless of the radiological findings. The investigators found that patients with a "target mismatch profile" (i.e., large areas of hypoperfusion with much smaller areas of restricted diffusion) benefited greatly from fibrinolysis if they achieved recanalization. Conversely, patients with very large areas of restricted diffusion had unacceptably high risks of intracerebral bleeding.

The randomized trial EPITHET assigned 101 patients to receive intravenous rt-PA or placebo 3-6 h after stroke onset (Davis et al., 2008). All patients were studied with MRI with DWI-PWI before and a few days after treatment, but the radiological findings did not affect treatment assignment. DWI-PWI was present in $86 \%$ of patients. Reperfusion occurred in 39\% of mismatch patients and these patients had less infarct growth and better functional out- come (defined as modified Rankin score $\leq 2$ at 90 days). The rate of symptomatic intracranial hemorrhage was quite low (4\%) and the risk of this complication did not correlate with baseline volume of restricted diffusion. In addition to DWI-PWI mismatch, there has been some interest in whether a clinical-diffusion mismatch (CDM, the comparison of severity of clinical deficits measured by NIHSS and area of restricted diffusion on MRI) can select patients for thrombolytic therapy. This was not supported in a substudy of EPITHET, in which there was no increased benefit from rt-PA in patients with CDM (Ebinger et al., 2009).

A recent study compared intravenous tenecteplase administered between 3 and $6 \mathrm{~h}$ from symptom onset on patients with documented penumbra (defined by MRI with DWI-PWI or CTP) and vessel occlusion (defined by non-invasive angiogram) versus control patients treated with intravenous rt-PA within $3 \mathrm{~h}$ according to current guidelines (Parsons et al., 2009). Although the relatively small size of the study ( $n=50$, included only 15 treated with tenecteplase) and methodological limitations preclude definite conclusions, the high degrees of reperfusion (74\%) and rates of recanalization (10/15 cases) among patients selected on the basis of penumbral imaging was promising. Pilot trials testing intravenous desmoteplase between 3 and $9 \mathrm{~h}$ from symptom onset in patients with DWI-PWI mismatch on baseline MRI had shown encouraging results (Hacke et al., 2005; Furlan et al., 2006). However, the larger DIAS-2 study did not confirm this benefit (Hacke et al., 2009). A preponderance of mild strokes with small core lesions and mismatch volumes may have limited the power of DIAS-2 to detect some therapeutic effect.

An ongoing trial (MR RESCUE) is assessing the value of endovascular reperfusion within 3-8 h of symptom onset among patients with DWI-PWI mismatch on MRI. At this point, we still do not have sufficient information to recommend the use of penumbral imaging to select patients for fibrinolysis in clinical practice.

\section{INTRA-ARTERIAL FIBRINOLYSIS AND BRIDGING THERAPY}

The study and application of endovascular reperfusion therapies for acute ischemic stroke has strong advocates. Unfortunately, available evidence is highly promising but not conclusive. Therefore, endovascular interventions for acute brain ischemia cannot be considered standard of care. This is a brief review of the most important information on intra-arterial fibrinolysis and combined intravenous and intra-arterial therapy (also known as bridging therapy).

The PROACT II study provides the best evidence that intraarterial fibrinolysis can improve patient outcomes (Furlan et al., 1999). This was a rigorously designed, multi-center ( 54 centers in USA and Canada), randomized, open-label study with blinded outcome assessment which enrolled 180 patients with angiographically proven middle cerebral artery occlusion and stroke symptoms for less than $6 \mathrm{~h}$ to receive intra-arterial pro-urokinase over $2 \mathrm{~h}$ plus intravenous heparin versus intravenous heparin alone (all patients received heparin for $4 \mathrm{~h}$ ). Mechanical disruption of the clot was not allowed. Intra-arterial fibrinolysis resulted in recanalization in $66 \%$ of cases. Favorable functional outcome (defined as modified Rankin score of $\leq 2$ ) at 90 days occurred in $40 \%$ of patients treated with intra-arterial fibrinolysis versus $25 \%$ of patients in the control group $(P=0.04$; number needed to treat $=7)$. These results were quite remarkable considering that participating patients had severe deficits at presentation (median NIHSS $=17$ ). The rate of symp- 
tomatic intracranial hemorrhage was $10 \%$ among patients treated with the fibrinolytic agent (versus $2 \%$ among controls), but there were no differences in mortality. Following the conclusion of the study, pro-urokinase was not approved for clinical use in stroke and its manufacturer stopped producing it. Over the subsequent years, clinical use of intra-arterial rt-PA has been found to be safe.

The Japanese MELT study had a similar design to PROACT II, albeit using urokinase as the fibrinolytic agent (Ogawa et al., 2007). It was prematurely aborted after enrollment of 114 patients because of the approval of intravenous rt-PA treatment in Japan. Clinical outcomes were more favorable with intra-arterial fibrinolysis, especially in terms of the number of patients achieving excellent function and minimal or no deficits at 90 days. Symptomatic intracranial hemorrhage occurred in $9 \%$ of fibrinolyzed patients (versus $2 \%$ of controls).

The combined results of PROACT II and MELT provide strong support for the clinical use of intra-arterial fibrinolysis. Yet, the advent of mechanical embolectomy afforded by the introduction of clot retrieving and suctioning catheters has changed the field. Today, endovascular reperfusion procedures start with attempts to remove the clot and fibrinolysis is usually only attempted as an adjuvant therapy when the clot cannot be mechanically retrieved or suctioned.

Bridging therapy consists of administering intravenous fibrinolysis and then proceeding to endovascular treatment if the patient fails to improve and there is persistent major intracranial vessel occlusion. The IMS II trial tested this strategy on 81 stroke patients with severe deficits at presentation (median NIHSS of 19) (The IMS II Trial Investigators , 2007). Intravenous rt-PA $(0.6 \mathrm{mg} / \mathrm{kg})$ was started within $3 \mathrm{~h}$ and intra-arterial rt-PA (up to $22 \mathrm{mg}$ ) within $5 \mathrm{~h}$ of symp-

\section{REFERENCES}

Adams, H. P. Jr., Del Zoppo, G., Alberts, M. J., Bhatt, D. L., Brass, L., Furlan, A., Grubb, R. L., Higashida, R. T., Jauch, E. C., Kidwell, C., Lyden, P. D., Morgenstern, L. B., Qureshi, A. I., Rosenwasser, R. H., Scott, P. A., and Widicks, E. F. (2007). Guidelines for the early management of adults with ischemic stroke: a guideline from the American Heart Association/ American Stroke Association Stroke Council, Clinical Cardiology Council, Cardiovascular Radiology and Intervention Council, and the Atherosclerotic Peripheral Vascular Disease and Quality of Care Outcomes in Research Interdisciplinary Working Groups: the American Academy of Neurology affirms the value of this guideline as an educational tool for neurologists. Stroke 38, 1655-1711.

Albers, G. W., Thijs, V. N., Wechsler, L., Kemp, S., Schlaug, G., Skalabrin, E., Bammer, R., Kakuda, W., Lansberg, M. G., Shuaib, A., Coplin, W., Hamilton, S., Moseley, M., and Marks, M. P. (2006). Magnetic resonance imaging profiles predict clinical response to early reperfusion: the diffusion and perfusion imaging evaluation for understanding stroke evolution
(DEFUSE) study. Ann. Neurol. 60, 508-517.

Barber, P. A., Zhang, J., Demchuk, A. M., Hill, M. D., and Buchan, A. M. (2001). Why are stroke patients excluded from TPA therapy? An analysis of patient eligibility. Neurology 56, 1015-1020.

Bluhmki, E., Chamorro, A., Davalos, A., Machnig, T., Sauce, C., Wahlgren, N., Wardlaw, J., and Hacke, W. (2009). Stroke treatment with alteplase given $3.0-4.5 \mathrm{~h}$ after onset of acute ischaemic stroke (ECASS III): additional outcomes and subgroup analysis of a randomized controlled trial. Lancet Neurol. 8, 1095-1102.

Bruno, A., Levine, S. R., Frankel, M. R., Brott, T. G., Lin, Y., Tilley, B. C., Lyden, P. D., Broderick, J. P., Kwiatkowski, T. G., and Fineberg, S. E. (2002). Admission glucose level and clinical outcomes in the NINDS rt-PA stroke trial. Neurology 59, 669-674.

Chernyshev, O. Y., Martin-Schild, S., Albright, K. C., Barreto, A., Misra, V., Acosta, I., Grotta, J. C., and Savitz, S. I. (2010). Safety of tPA in stroke mimics and neuroimaging-negative cerebral ischemia. Neurology 74, 1730-1345.

Davis, S. M., Donnan, G. A., Parsons, M. W., Levi, C., Butcher, K. S., Peeters, A., Barber, P. A., Bladin, C., De Silva,

tom onset. Patients treated in this multi-center, open-label, single arm pilot study had better outcomes than the rt-PA-treated patients in the NINDS study despite longer time to start of intravenous fibrinolysis and much worse initial stroke severity. The rate of symptomatic intracranial hemorrhage was nearly $10 \%$, but 3 month mortality was actually lower than expected (16\%). IMS III is randomizing patients to standard intravenous rt-PA versus combined intravenous/intraarterial approach (including mechanical embolectomy).

\section{CLINICAL PEARLS}

- Intravenous fibrinolysis is an effective treatment for acute ischemic stroke for up to $4.5 \mathrm{~h}$ after symptom onset.

- Time from symptom onset to fibrinolytic therapy is the most important determinant of the success of treatment; the chances of favorable recovery diminish with each minute lost.

- Strict adherence to the prescribed protocol for the administration of rt-PA and post-fibrinolytic care is crucial to minimize the risk of hemorrhagic complications.

- rt-PA remains the only fibrinolytic agent reliably proven to improve the outcomes of stroke patients after intravenous administration.

- Selection of candidates for reperfusion therapies using penumbra imaging (MRI with DWI-PWI or CTP) is a promising - albeit yet unproven - strategy to widen the therapeutic window for acute treatment of brain ischemia.

- Correction of hyperglycemia might improve the results of fibrinolysis and should be considered as part of the acute care of stroke patients undergoing reperfusion therapies.

D. A., Byrnes, G., Chalk, J. B., Fink, J. N., Kimber, T. E., Schultz, D., Hand, P. J., Frayne, J., Hankey, G., Muir K., Gerraty, R., Tress, B. M., and Desmond, P. M. (2008). Effects of alteplase beyond $3 \mathrm{~h}$ after stroke in the echoplanar imaging thrombolytic evaluation trial (EPITHET): a placebo-controlled randomised trial. Lancet Neurol. 7, 299-309.

Derex, L., Hermier, M., Adeleine, P., Pialat, J. B., Wiart, M., Berthezene, Y., Philippeau, F., Honnorat, J., Froment, J. C., Trouillas, P., and Nighoghossian, N. (2005). Clinical and imaging predictors of intracerebral haemorrhage in stroke patients treated with intravenous tissue plasminogen activator. J. Neurol. Neurosurg. Psychiatr. 76, 70-75.

Ebinger, M., Iwanaga, T., Prosser, J. F., De Silva, D. A., Christensen, S., Collins, M., Parsons, M. W., Levi, C. R., Bladin, C. F., Barber, P. A., Donnan, G. A., and Davis, S. M. (2009). Clinical-diffusion mismatch and benefit from thrombolysis 3 to 6 hours after acute stroke. Stroke 40, 2572-2574.

Furlan, A., Higashida, R., Wechsler, L., Gent, M., Rowley, H., Kase, C., Pessin, M., Ahuja, A., Callahan, F., Clark, W. M., Silver, F., and Rivera, F. (1999).
Intra-arterial prourokinase for acute ischemic stroke. The PROACT II study: a randomized controlled trial. Prolyse in acute cerebral thromboembolism. JAMA 282, 2003-2011.

Furlan, A. J., Eyding, D., Albers, G. W., Al Rawi, Y., Lees, K. R., Rowley, H. A., Sachara, C., Soehngen, M., Warach, S., and Hacke, W. (2006). Dose escalation of desmoteplase for acute ischemic stroke (DEDAS): evidence of safety and efficacy 3 to 9 hours after stroke onset. Stroke 37, 1227-1231.

Hacke, W., Albers, G., Al Rawi, Y. Bogousslavsky, J., Davalos, A., Eliasziw, M., Fischer, M., Furlan, A., Kaste, M., Lees, K. R., Soehngen, M., and Warach, S. (2005). The desmoteplase in acute ischemic stroke trial (DIAS): a phase II MRI-based 9-hour window acute stroke thrombolysis trial with intravenous desmoteplase. Stroke 36, 66-73.

Hacke, W., Donnan, G., Fieschi, C., Kaste, M., von Kummer, R., Broderick, J. P., Brott, T., Frankel, M., Grotta, J. C., Haley, E. C. Jr., Kwiatkowski, T., Levine, S. R., Lewandowski, C., Lu, M., Lyden, P., Marler, J. R., Patel, S., Tilley, B. C., Albers, G., Bluhmki, E., Wilhelm, M., and Hamilton, S. (2004). Association of outcome with early stroke treatment: pooled analysis of ATLANTIS 
ECASS, and NINDS rt-PA stroke trials. Lancet 363, 768-774.

Hacke, W., Furlan, A. J., Al Rawi, Y., Davalos, A., Fiebach, J. B., Gruber, F., Kaste, M., Lipka, L .J., Pedraza, S., Ringleb, P.A., Rowley, H.A., Schneider, D., Schwamm, L.H.,Leal,J.S., Söhngen, M., Teal, P. A., Wilhelm-Ogunbiyi, K., Wintermark, M., and Warach, S. (2009). Intravenous desmoteplase in patients with acute ischaemic stroke selected by MRI perfusion-diffusion weighted imaging or perfusion CT (DIAS-2): a prospective, randomised, double-blind, placebo-controlled study. Lancet Neurol. 8, 141-150.

Hacke, W., Kaste, M., Bluhmki, E., Brozman, M., Davalos, A., Guidetti, D., Larrue, V., Lees, K. R., Medeghri, Z., Machnig, T., Schneider, D., von Kummer, R., Wahlgren, N., Toni, D. (2008). Thrombolysis with alteplase 3 to 4.5 hours after acute ischemic stroke. N. Engl. J. Med. 359, 1317-1329.

Heuschmann, P. U., Kolominsky-Rabas, P. L., Roether, J., Misselwitz, B., Lowitzsch, K., Heidrich, J., Hermanek, P., Leffmann, C., Sitzer, M., Biegler, M., Buecker-Nott, H. J., and Berger, K. (2004). Predictors of in-hospital mortality in patients with acute ischemic stroke treated with thrombolytic therapy. JAMA 292, 1831-1838.

Katzan, I. L., Furlan, A. J., Lloyd, L. E., Frank, J. I., Harper, D. L., Hinchey, J. A., Hammel, J.P., Qu, A., and Sila, C. A. (2000). Use of tissue-type plasminogen activator for acute ischemic stroke: the cleveland area experience. JAMA 283, 1151-1158.

Kidwell, C. S., Saver, J. L., Carneado, J., Sayre, J., Starkman, S., Duckwiler, G., Gobin, Y. P., Jahan, R., Vespa, P., Villablanca, J.P., Liebeskind, D. S., and Vinuela, F. (2002). Predictors of hemorrhagic transformation in patients receiving intra-arterial thrombolysis. Stroke 33, 717-724.

Kwiatkowski, T. G., Libman, R. B., Frankel, M., Tilley, B. C., Morgenstern, L. B., Lu, M., Broderick, J. P., Lewandowsi, C. A., Marler, J. R., Levine, S. R., and Brott, T. (1999). Effects of tissue plasminogen activator for acute ischemic stroke at one year. National Institute of
Neurological Disorders and Stroke Recombinant Tissue Plasminogen Activator Stroke Study Group. N. Engl. J. Med. 340, 1781-1787.

Leigh, R., Zaidat, O. O., Suri, M. F., Lynch, G., Sundararajan, S., Sunshine, J. L., Tarr, R., Selman, W., Landis, D. M., and Suarez,J.I. (2004). Predictors of hyperacute clinical worsening in ischemic stroke patients receiving thrombolytic therapy. Stroke 35, 1903-1907.

Marler,J.R., Tilley, B. C., Lu, M., Brott, T. G., Lyden, P.C., Grotta, J.C., Broderick, J.P., Levine, S. R., Frankel, M. P., Horowitz, S. H., Haley, E. C. Jr., Lewandowski, C. A., and Kwiatkowski, T. P. (2000). Early stroke treatment associated with better outcome: the NINDS rt-PA stroke study. Neurology 55, 1649-1655.

Mateen, F. J., Buchan, A. M., and Hill, M. D. (2010). Outcomes of thrombolysis for acute ischemic stroke in octogenarians versus non-agenarians. Stroke 41, 1833-1835.

Mateen, F. J., Nasser, M., Spencer, B. R., Freeman, W. D., Shuaib, A., Demaerschalk, B. M., and Wijdicks, E. F. (2009). Outcomes of intravenous tissue plasminogen activator for acute ischemic stroke in patients aged 90 years or older. Mayo Clin. Proc. 84, 334-338.

Meschia, J. F., Miller, D. A., and Brott, T. G. (2002). Thrombolytic treatment of acute ischemic stroke. Mayo Clin. Proc. 77, 542-551.

Muir, K. W., Buchan, A., von Kummer, R., Rother, J., and Baron, J. C. (2006). Imaging of acute stroke. Lancet Neurol. 5, 755-768.

NINDS rt-PA Stroke Study Group. (1995). Tissue plasminogen activator for acute ischemic stroke. The national institute of neurological disorders and stroke rt-PA stroke study group. N. Engl. J. Med. 333, 1581-1587.

Ogawa, A., Mori, E., Minematsu, K., Taki, W., Takahashi, A., Nemoto, S., Miyamoto, S., Sasaki, M., and Inoue, T. (2007). Randomized trial of intraarterial infusion of urokinase within 6 hours of middle cerebral artery stroke: the middle cerebral artery embolism local fibrinolytic intervention trial (MELT) Japan. Stroke 38, 2633-2639.
Parsons, M. W., Miteff, F., Bateman, G. A., Spratt, N., Loiselle, A., Attia, J. and Levi, C. R. (2009). Acute ischemic stroke: imaging-guided tenecteplase treatment in an extended time window. Neurology 72, 915-921.

Qureshi, A. I., Ezzeddine, M. A., Nasar, A., Suri, M. F., Kirmani, J. F., Janjua, N., and Divani, A. A. (2006). Is IV tissue plasminogen activator beneficial in patients with hyperdense artery sign? Neurology 66, 1171-1174.

Ribo, M.,Molina, C., Montaner,J., Rubiera, M., Delgado-Mederos, R., Arenillas, J. F., Quintana, M., and Alvarez-Sabín, J. (2005). Acute hyperglycemia state is associated with lower PA-induced recanalization rates in stroke patients. Stroke 36, 1705-1709.

Rost, N. S., Masrur, S., Pervez, M. A., Viswanathan, A., and Schwamm, L. H. (2009). Unsuspected coagulopathy rarely prevents IV thrombolysis in acute ischemic stroke. Neurology 73, 1957-1962.

Saposnik, G., Young, B., Silver, B., Di Legge, S., Webster, F., Beletsky, V., Jain, V., Nilanont, Y., and Hachinski, V. (2004). Lack of improvement in patients with acute stroke after treatment with thrombolytic therapy: predictors and association with outcome. JAMA 292, 1839-1844.

Saver, J. L. (2007). Hemorrhage after thrombolytic therapy for stroke: the clinically relevant number needed to harm. Stroke 38, 2279-2283.

Sylaja, P. N., Cote, R., Buchan, A. M., and Hill, M. D. (2006). Thrombolysis in patients older than 80 years with acute ischaemic stroke: Canadian alteplase for stroke effectiveness study. J. Neurol. Neurosurg. Psychiatr. $77,826-829$.

The IMS II Trial Investigators. (2007). The interventional management of stroke (ims) II study. Stroke 38, 2127-2135.

von Kummer, R., and Hacke, W. (1992). Safety and efficacy of intravenous tissue plasminogen activator and heparin in acute middle cerebral artery stroke. Stroke 23, 646-652.

Wahlgren, N., Ahmed, N., Davalos, A., Ford, G. A., Grond, M., Hacke, W., Millan, M., Muir, K., Roine, R.
O., Toni, D., and Lees, K. R. (2007). Thrombolysis with alteplase for acute ischaemic stroke in the safe implementation of thrombolysis in strokemonitoring study (SITS-MOST): an observational study. Lancet 369, 275-282.

Wahlgren, N., Ahmed, N., Davalos, A., Hacke, W., Millan, M., Muir, K., Roine, R. O., Toni, D., and Lees, K. R. (2008a). Thrombolysis with alteplase $3-4.5 \mathrm{~h}$ after acute ischaemic stroke (SITSISTR): an observational study. Lancet 372, 1303-1309.

Wahlgren, N., Ahmed, N., Eriksson, N. Aichner, F., Bluhmki, E., Davalos, A., Erila, T., Ford, G. A., Grond, M., Hacke, W., Hennerici, M. G., Kaste, M., Kohrmann, M., Larrue, V., Lees, K. R., Machnig, T., Roine, R. O., Toni, D., and Vanhooren, G. (2008b). Multivariable analysis of outcome predictors and adjustment of main outcome results to baseline data profile in randomized controlled trials: safe implementation of thrombolysis in stroke-monitoring study (SITS-MOST). Stroke 39, 3316-3322.

Conflict of Interest Statement: The authors declare that the research was conducted in the absence of any commercial or financial relationships that could be construed as a potential conflict of interest.

Received: 08 September 2010; paper pending published: 15 September 2010; accepted: 06 October 2010; published online: 29 October 2010.

Citation: Fugate JE, Giraldo EA and Rabinstein AA (2010) Thrombolysis for cerebral ischemia. Front. Neur. 1:139. doi: 10.3389/fneur.2010.00139

This article was submitted to Frontiers in Neurocritical and Neurohospitalist Care, a specialty of Frontiers in Neurology.

Copyright (๑) 2010 Fugate, Giraldo and Rabinstein. This is an open-access article subject to an exclusive license agreement between the authors and the Frontiers Research Foundation, which permits unrestricted use, distribution, and reproduction in any medium, provided the original authors and source are credited. 